\title{
Elicitor-induced rosmarinic acid biosynthesis in Lithospermum erythrorhizon cell suspension cultures: Activities of rosmarinic acid synthase and the final two cytochrome P450-catalyzed hydroxylations
}

\author{
Ayako Ogata ${ }^{a}$, Ayako Tsuruga, Michiyo Matsunob, Hajime Mizukami* \\ Graduate School of Pharmaceutical Sciences, Nagoya City University, Nagoya, Aichi 467-8603, Japan \\ *E-mail: hajimem@phar.nagoya-cu.ac.jp Tel: +81-52-836-3415 Fax: +81-52-836-3415
}

Received September 13, 2004; accepted October 6, 2004 (Edited by K. Yazaki)

\begin{abstract}
A drastic increase in rosmarinic acid (RA) accumulation is induced in cultured cells of Lithospermum erythrorhizon after their exposure to yeast extract or methyl jasmonate. Addition of the elicitors to the cell cultures only slightly enhanced the activity of rosmarinic acid synthase, which catalyzes formation of 4-coumaroyl-4'hydroxyphenyllactic acid (CHPL), the first reaction specific to RA biosynthesis. In contrast, the two-step cytochrome P450catalyzed hydroxylations of CHPL to form RA were dramatically up-regulated by the elicitor treatments, indicating that these hydroxylation activities are likely to play a key regulatory role in elicitation of RA biosynthesis.
\end{abstract}

Key words: Lithospermum erythrorhizon, rosmarinic acid biosynthesis, rosmarinic acid synthase, cytochrome P450catalyzed hydroxylation.

Rosmarinic acid (RA), $\alpha$-O-caffeoyl-3', 4'-dihydroxyphenyllactic acid, is a well-known hydroxycinnamic acid ester that occurs across a wide range of plant families, including the Boraginaceae and Lamiaceae (Petersen and Simmonds 2003). The biosynthesis and production of RA in cultured plant cells have been extensively studied because RA exhibits various pharmacological activities, including potent antioxidative properties which make it a potentially useful compound as a medicine and a food additive. The biosynthetic pathway leading to RA is well defined, as shown in Figure 1. Condensation of 4-hydroxyphenyllactic acid (derived from tyrosine) with 4coumaroyl CoA (derived from phenylalanine) is catalyzed by an acyltransferase named rosmarinic acid synthase (RAS) to yield 4-coumaroyl-4'-hydroxyphenyllactic acid (CHPL). CHPL is then converted to RA by two consecutive hydroxylation steps, each of which is catalyzed by distinct cytochrome $\mathrm{P} 450 \mathrm{~s}$ ( $3 \mathrm{H}$ and $\left.3^{\prime} \mathrm{H}\right)$.

RA production in cultured plant cells was earlier shown to be enhanced by addition of elicitors such as yeast extract (YE) and methyl jasmonate (MJ), as exemplified in Lithospermum erythrorhizon cell cultures
(Mizukami et al. 1992 and 1993). Elicitation by YE or MJ up-regulated the activities of both phenylalanine ammonia-lyase (PAL) and 4-hydroxyphenylpyruvate reductase (HPR), entrypoint enzymes for the phenylpropanoid pathway and tyrosine-derived pathway, respectively. Not all steps in the biosynthetic pathway respond to elicitation, since neither the expression level of cinnamic acid 4-hydroxylase (Yamamura et al. 2001) nor the activities of tyrosine aminotransferase (Mizukami et al. 1993) were affected by elicitor treatment in L. erythrorhizon cells. However, little is known whether the enzyme activities involved in the three final steps in the RA biosynthesis (RAS, $3 \mathrm{H}$ and $3^{\prime} \mathrm{H}$ ) are affected by elicitors. In the present investigation we analyzed the effect of elicitor treatment on these three enzyme activities, and conclude that the two final hydroxylation steps are likely to play key roles in regulating elicitor-induced RA biosynthesis in $L$. erythrorhizon cell suspension cultures.

Suspension cultures of $L$. erythrorhizon were maintained in LS liquid medium (Linsmaier and Skoog 1965) supplemented with $1 \mu \mathrm{M}$ 2,4-dichlorophenoxyacetic acid and $1 \mu \mathrm{M}$ kinetin. Cell suspension $(5 \mathrm{ml})$ was transferred into $25 \mathrm{ml}$ fresh medium in a $100 \mathrm{ml}$

\footnotetext{
${ }^{a}$ Present Address: San-Ei Gen F. F. I., Inc., 1-1-11 Sanwa-cho, Toyonaka 561-8588, Japan

${ }^{\mathrm{b}}$ Present Address: Donald Danforth Plant Science Center, 975 N. Warson Rd., St Louis MO 63132, U.S.A.

Abbreviations: 3H, 4-coumaroyl-4'-hydroxyphenyllactic acid 3-hydroxylase; 3'H, caffeoyl-4-hydroxyphenyllactic acid 3'-hydroxylase; CHPL, 4coumaroyl-4'-hydroxyphenyllactic acid; CaHPL, caffeoyl-4'-hydroxyphenyllactic acid; HPR, 4-hydroxyphenylpyruvate reductase; MJ, methyl jasmonate; PAL, phenylalanine ammonia-lyase; RA, rosmarinic acid; RAS, rosmarinic acid synthase; YE, yeast extract.
} 


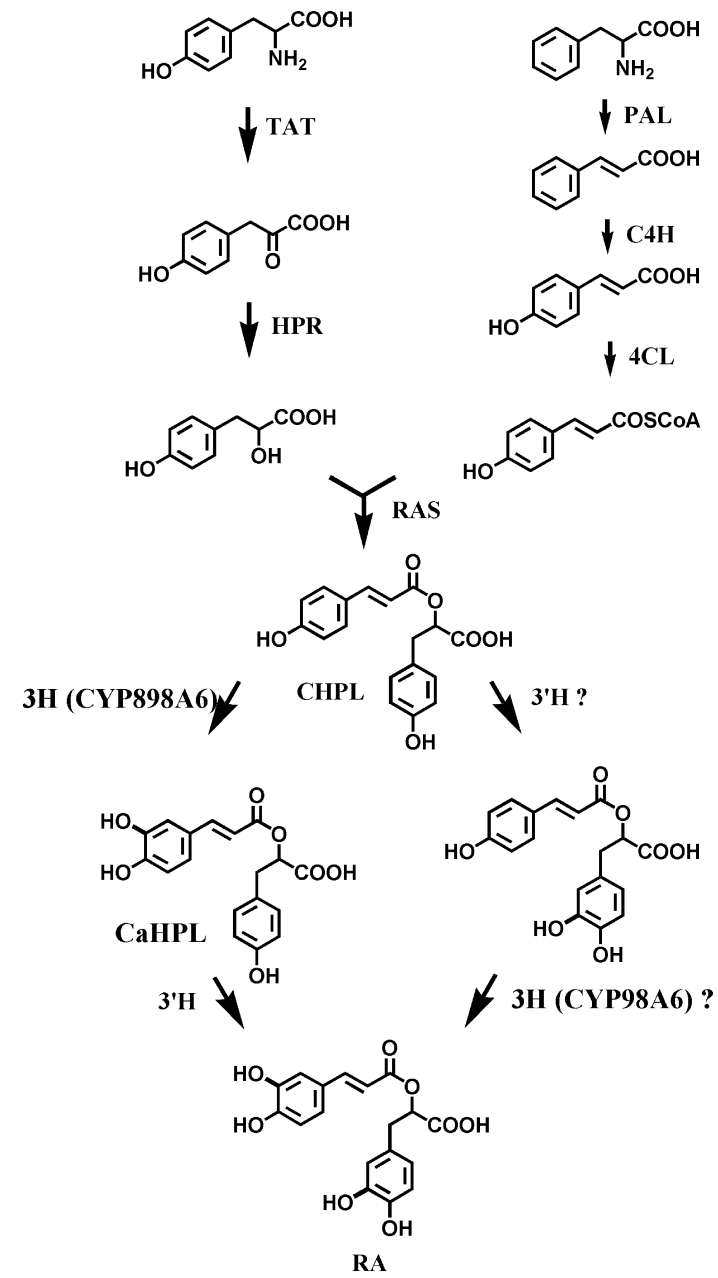

Figure 1. The proposed biosynthetic pathway leading to rosmarinic acid. PAL, phenylalanine ammonia-lyase; $\mathrm{C} 4 \mathrm{H}$, cinnamic acid 4hydroxylase; 4CL, 4-coumaric acid:CoA ligase; TAT, tyrosine aminotransferase; HPR, 4-hydroxyphenylpyruvate reductase; RAS, rosmarinic acid synthase, $3 \mathrm{H}$, 4-coumaroyl-4'-hydroxyphenyllactic acid 3-hydroxylase; 3'H, caffeoyl-4'-hydroxyphenyllactic acid $3^{\prime}-$ hydroxylase; CHPL, 4-coumaroyl-4'-hydroxyphenyllactic acid; CaHPL, caffeoyl-4'-hydroxyphenyllactic acid; RA, rosmarinic acid.

Erlenmeyer flask at 14-day intervals and cultured on a rotary shaker at $25^{\circ} \mathrm{C}$ in the dark. YE (Difco) was dissolved in water, autoclaved at $120^{\circ} \mathrm{C}$ for $20 \mathrm{~min}$, and aseptically added to the cell suspension at a final concentration of $5 \mathrm{gl}^{-1}$. MJ (Tokyo Kasei) was dissolved in dimethylsulfoxide and added to the cultures through a membrane filter to give a final concentration of $100 \mu \mathrm{M}$. These elicitors were added to the cells 7 days after cell transfer and the cells were collected by vacuum filtration at defined times, immediately frozen in liquid nitrogen, and stored at $-75^{\circ} \mathrm{C}$ until use.

Preparation of soluble enzyme and microsome fractions was carried out at $0-4^{\circ} \mathrm{C}$. The frozen cells were homogenized in $100 \mathrm{mM}$ potassium phosphate buffer, $\mathrm{pH}$ 7.0, containing $1 \mathrm{mM}$ DTT, $5 \mathrm{mM}$ EDTA, $0.5 \mathrm{M}$ sorbitol and $30 \mathrm{gl}^{-1}$ polyvinylpolypyrrolidone. The homogenate was filtered through two layers of Miracloth
(Calbiochem) and centrifuged at $12,000 \mathrm{~g}$ for $20 \mathrm{~min}$. PAL and RAS were precipitated from the supernatant with $80 \%$ ammonium sulfate saturation. Precipitated protein was dissolved in the extraction buffer containing $0.3 \mathrm{M}$ sodium chloride. The solution was desalted on a Sephadex G-25 column and used as the soluble enzyme fraction.

For preparation of the microsome fraction, the supernatant from the $12,000 \mathrm{~g}$ centrifugation was centrifuged again at $100,000 \mathrm{~g}$ for $60 \mathrm{~min}$. The pellet was suspended in $100 \mathrm{mM}$ potassium phosphate buffer, $\mathrm{pH}$ 7.0, containing $3.5 \mathrm{mM} \mathrm{2-mercaptoethanol} \mathrm{and} 0.5 \mathrm{M}$ sorbitol, and this slurry was applied to a Sephadex G-25 column. The fraction eluting at the void volume was collected and centrifuged again at $100,000 \mathrm{~g}$ for $60 \mathrm{~min}$. This pellet was re-suspended in the same buffer and used as the microsomal fraction. The protein content in the soluble and microsomal fractions was estimated by the method of Bradford (Bradford 1976).

PAL was assayed by the spectrophotometric method (Edwards and Kessmann 1992), while the RAS assay was carried out according to the method described by Szabo et al. (1999) with slight modifications as follows. Soluble enzyme preparation $(25 \mu \mathrm{l})$ was added to $25 \mu \mathrm{l}$ aliquots of RAS reaction mixture $(100 \mathrm{mM}$ potassium phosphate (pH 7.0) containing $0.1 \mathrm{mM}$ DTT, $1 \mathrm{mM}$ ascorbic acid, $1 \mathrm{mM}$ 4-coumaroyl $\mathrm{CoA}$ and $0.4 \mathrm{mM} 4$ hydroxyphenyllactic acid) and incubated for $30 \mathrm{~min}$ at $30^{\circ} \mathrm{C}$. 4-Coumaroyl $\mathrm{CoA}$ was synthesized according to the method of Stöckigt and Zenk (1975). The RAS reaction was terminated by adding $4 \mu \mathrm{l} 5 \mathrm{M} \mathrm{HCl}$, and the acidified mixture was extracted with $50 \mu 1$ ethyl acetate three times. The combined ethyl acetate extract was evaporated and the residue was dissolved in $50 \mu 1$ methanol containing $0.1 \%(\mathrm{v} / \mathrm{v})$ acetic acid. The amount of CHPL was estimated by HPLC. Conditions for HPLC are as follows: COSMOSIL 5C18-MS (Nacalai Tesque) $150 \times 4.6 \mathrm{~mm}$; solvent system, methanol- $0.1 \%$ acetic acid (50: 50); flow rate, $1.0 \mathrm{ml}$; detection; $310 \mathrm{~nm}$.

To estimate the hydroxylation activity, the microsome preparation $(50 \mu \mathrm{l})$ was added to $250 \mu \mathrm{l}$ aliquots of hydroxylation reaction mixture $(100 \mathrm{mM}$ potassium phosphate, $\mathrm{pH} 7.0$, containing $80 \mu \mathrm{M}$ CHPL and $0.8 \mathrm{mM}$ $\mathrm{NADPH}$ ) and incubated for $30 \mathrm{~min}$ at $20^{\circ} \mathrm{C}$. CHPL was prepared as described previously (Matsuno et al. 2001). The reaction was terminated by adding $20 \mu \mathrm{l} 5 \mathrm{M} \mathrm{HCl}$, and the acidified mixture was extracted with $600 \mathrm{ml}$ ethyl acetate three times. The combined ethyl acetate extract was evaporated, and the residue was dissolved in $25 \mathrm{ml}$ methanol containing $0.1 \%(\mathrm{v} / \mathrm{v})$ acetic acid. The amount of RA formed by the enzymatic reaction was determined by HPLC according to the previously described method (Mizukami et al. 1992).

For quantitative determination of RA, frozen cells (about $0.2 \mathrm{~g}$ ) were extracted with $2 \mathrm{ml}$ methanol at 
(A)

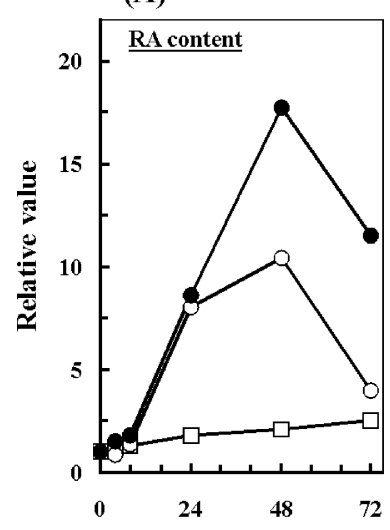

(B)

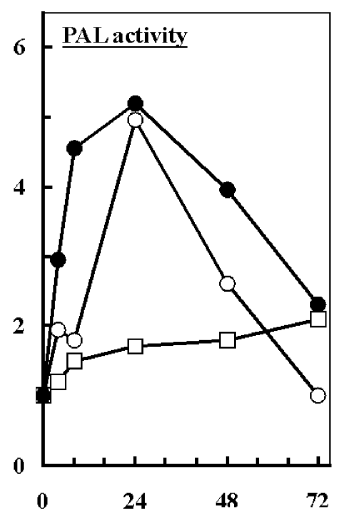

(C)

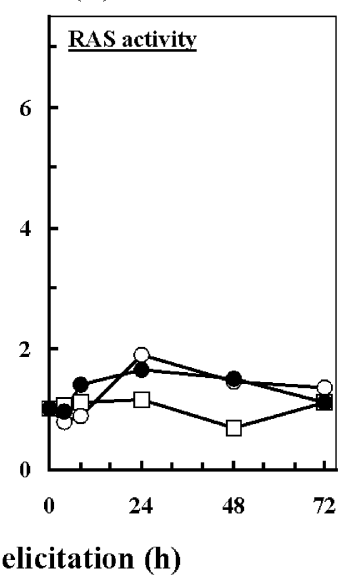

(D)

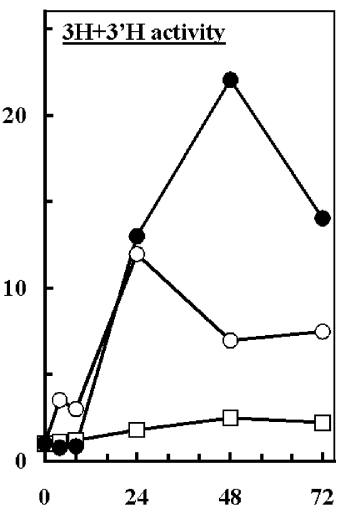

Time after elicitation (h)

Figure 2. Changes in RA content (A), and PAL (B), RAS (C) and 3H plus 3'H (D) activities in cultured cells of Lithospermum erythrorhizon treated with methyl jasmonate (closed circles) or yeast extract (open circles) 7 days after cell inoculation. The control cells (open squares) were treated with dimethylsulfoxide. Each point indicates a value relative to the value at $0 \mathrm{~h}$ (just before elicitation). RA content, and PAL, RAS and $3 \mathrm{H}$ plus $3^{\prime} \mathrm{H}$ activities at $0 \mathrm{~h}$ were $0.02 \%$ of the cell fresh weight, $29.4 \mathrm{pkat} \mathrm{mg}^{-1}$ protein, $5.2 \mathrm{pkat} \mathrm{mg}^{-1} \mathrm{protein}$ and $0.15 \mathrm{pkat}^{\mathrm{mg}}{ }^{-1} \mathrm{protein}$, respectively. Each point represents an average from duplicate cultures. The entire experiment was repeated twice with the essentially the same result, and one representative data set is shown here.

$65^{\circ} \mathrm{C}$ for $1 \mathrm{~h}$ with vigorous shaking. The slurry was centrifuged at $12,000 \mathrm{~g}$ for $5 \mathrm{~min}$ and the supernatant was subjected to HPLC analysis (Mizukami et al. 1992).

Addition of $\mathrm{YE}$ or $\mathrm{MJ}$ rapidly and transiently enhanced accumulation of RA in $L$. erythrorhizon suspension cultures (Figure 2A). In the YE-treated cells, the RA content reached a maximum between 24 and $48 \mathrm{~h}$ after treatment and the extent of the increase in the RA content was about 4-fold higher than the content of the control cells. In the MJ-treated cells RA accumulation reached a maximum $48 \mathrm{~h}$ after treatment and the RA content was about 10 -fold higher than that in the control cells. The RA content was then decreased between 48 and $72 \mathrm{~h}$ after elicitor addition. RA might be metabolized to some other compounds although such peaks could not be detected under the present HPLC condition. These results are essentially consistent with those described previously (Mizukami et al. 1993).

A crude enzyme preparation from cultured $L$. erythrorhizon cells catalyzed condensation of 4coumaroyl CoA with 4-hydroxyphenyllactic acid to form CHPL in a protein- and incubation time-dependent manner, thus indicating the presence of RAS activity. The activity of RAS was only slightly enhanced by either YE- or MJ-treatment, in contrast to PAL activity which was rapidly and transiently induced by both elicitor treatments (Figure 2B and 2C).

CHPL, a product of the reaction catalyzed by RAS, is converted to RA by two consecutive hydroxylation reactions. When CHPL was incubated with the microsome preparation from L. erythrorhizon cells in the presence of NADPH at $20^{\circ} \mathrm{C}$ for $30 \mathrm{~min}$, accumulation of RA in the reaction mixture could be detected by HPLC. Shorter incubation for 5 to $10 \mathrm{~min}$ yielded, together with
RA, an additional product whose retention time and UVspectrum were consistent with those of caffeoyl-4'hydroxyphenyllactic acid (CaHPL). The identity of the HPLC peak with CaHPL was further confirmed by measuring ${ }^{1} \mathrm{H}-\mathrm{NMR}$ spectrum of the pooled eluate. The microsomes did not produce RA from CHPL in the absence of NADPH. Furthermore, both CaHPL and RA formation were completely inhibited by the addition of $2 \mathrm{mM}$ miconazole, a cytochrome P450 inhibitor (data not shown).

The enzymatic formation of RA from CHPL was drastically and transiently induced by elicitor treatments as shown in Figure 2D. In the YE-treated cells the activity reached a maximum $24 \mathrm{~h}$ after YE-addition and was about 7-fold higher than that of the control. In the MJ-treated cells the peak activity was reached later $(48 \mathrm{~h}$ after treatment) and was 10-fold higher than that of the control cells.

Since the first report that RA production could be enhanced by the addition of YE to the cell cultures of Orthosiphon arisatus (Sumaryono et al. 1991), biochemical and molecular biological characterization of elicitation of RA biosynthesis has been extensively investigated using L. erythrorhizon (Boraginaceae) and Coleus blumei (Lamiaceae) cell cultures. We have shown that PAL in the phenylpropanoid pathway and HPR in the tyrosine-derived pathway were responsible for the elicitor-enhanced RA production in L. erythrorhizon cells (Mizukami et al. 1993). These results were later confirmed using C. blumei cells (Szabo et al. 1999).

In the present investigation we have examined the effects of elicitor treatment on the enzyme activities involved in final three steps in RA biosynthesis using $L$. erythrorhizon cell cultures. The activity of RAS in 
transferring the 4-coumaroyl moiety of 4-coumaroyl CoA to 4-hydroxyphenyllactic acid was only slightly enhanced by either YE- or MJ-addition to the cultures, even though this enzyme catalyzes the first reaction specific to RA biosynthesis. This result is consistent with an earlier report that RAS activity was largely unaffected by elicitor addition to C. blumei cells (Szabo et al. 1999).

The two consecutive hydroxylation steps that convert CHPL to RA were first shown to be catalyzed by two different cytochrome $\mathrm{P} 450 \mathrm{~s}$ (designated $3 \mathrm{H}$ and $3^{\prime} \mathrm{H}$ ) in C. blumei cells (Petersen 1997). A cytochrome P450 (CYP98A6) cDNA clone coding for $3 \mathrm{H}$ was subsequently isolated from $L$. erythrorhizon and expression of the corresponding gene was shown to be drastically up-regulated by addition of YE or MJ to $L$. erythrorhizon cells (Matsuno et al. 2002). In the present study we estimated these hydroxylation activities by measuring the rate of RA production from CHPL by microsome preparations in the presence of NADPH, an approach that reports the total activity of $3 \mathrm{H}$ and $3^{\prime} \mathrm{H}$. The $3 \mathrm{H}$ plus $3^{\prime} \mathrm{H}$ activity in L. erythrorhizon cells was dramatically increased by YE or MJ-addition. The extent of the increase in the hydroxylation activity was much higher than that seen for PAL and HPR activities and was proportional to the increase in RA content. This indicates that the microsomal hydroxylations of CHPL are likely to play key roles in regulation of elicitor-induced RA biosynthesis in L. erythrorhizon.

The order of introduction of the 3- and 3'-hydroxyl groups into CHPL remains unresolved, as does the question whether the activity and/or mRNA expression of both $3 \mathrm{H}$ and $3^{\prime} \mathrm{H}$ are both enhanced by elicitors. Our preliminary results from short-term incubation of CHPL with the microsomes, where we detected a product tentatively identified as CaHPL, as well as the recent report of the natural occurrence of CaHPL (isorinic acid) in plants (Helicteres isora) (Satake et al. 1999) suggests that the 3-hydroxyl group may be introduced first, converting CHPL to CaHPL, which would then be converted to RA by 3'-hydroxylation. Since CHPL was efficiently converted to RA by microsomes prepared from MJ-treated cells, without accumulation of the putative intermediate, it would appear that both $3 \mathrm{H}$ and $3^{\prime} \mathrm{H}$ activities are increased by elicitors. However, identification and characterization of $3^{\prime} \mathrm{H}$ is necessary to unambiguously resolve these questions.

\section{Acknowledgement}

One of the authors (HM) is grateful to late Dr. Mamoru Tabata, Professor Emeritus of Kyoto University, for his continuous encouragement to the author's research activities in the field of plant secondary metabolism. We also thank Professor Brian Ellis,
University of British Columbia, for critical reading of the manuscript. This work was supported in part by a Grant-in-Aid for High-Tech Research Center Project from the Ministry of Education, Culture, Sports, Science and Technology of Japan.

\section{References}

Bradford MM (1976) A rapid and sensitive method for the quantitation of microgram quantities of protein utilizing the principle of protein-dye binding. Anal Biochem 72: 248-254

Edwards R, Kessmann H (1992) Isoflavonoid phytoalexins and their biosynthetic enzymes. In: Gurr SJ et al. (eds): Molecular Plant Pathology A Practical Approach Vol. 2, IRL PRESS, Oxford, pp 45-62

Kim KH, Janik V, Petersen M (2004) Purification, cloning and functional expression of hydroxyphenylpyruvate reductase involved in rosmarinic acid biosynthesis in cell cultures of Coleus blumei. Plant Mol Biol 54: 311-323

Lismaier EM, Skoog F (1965) Organic growth factor requirements of tobacco tissue cultures. Physiol Plant 18: 100-127

Matsuno M, Nagatsu A, Ogihara Y, Mizukami H (2001) Synthesis of 2-O-(4-coumaroyl)-3-(4-hydroxyphenyl)lactic acid, an important intermediate of rosmarinic acid biosynthesis. Chem Pharm Bull 49: 1644-1646

Matsuno M, Nagatsu A, Ogihara Y, Ellis BE, Mizukami H (2002) CYP98A6 from Lithospermum erythrorhizon encodes 4coumaroyl-4'-hydroxyphenyllactic acid 3-hydroxylase involved in rosmarinic acid biosynthesis. FEBS Lett 514: 219-224

Mizukami H, Ogawa T, Ohashi H, Ellis BE (1992) Induction of rosmarinic acid biosynthesis in Lithospermum erythrorhizon cell suspension cultures by yeast extract. Plant Cell Rep 11: 480-483

Mizukami H, Tabira Y, Ellis BE (1993) Methyl-jasmonate-induced rosmarinic acid biosynthesis in Lithospermum erythrorhizon cell suspension cultures. Plant Cell Rep 12: 706-709

Petersen M (1997) Cytochrome-P450 dependent hydroxylation in the biosynthesis of rosmarinic acid in Coleus. Phytochemistry 45: 1165-1172

Petersen M, Simmonds MS (2003) Rosmarinic acid. Phytochemistry 62: 121-125

Satake T, Kamiya K, Saiki Y, Hama T, Fujimoto Y, Kitanaka S, Kimura Y, Uzawa J, Endang H, Umar M (1999) Studies on the constituents of fruits of Helicteres isora L. Chem Pharm Bull 47: 1444-1447

Stöckigt J, Zenk MH (1975) Chemical synthesis and properties of hydroxycinnamoyl-coenzyme A derivatives. Z Naturforsch 30c: $352-358$

Szabo E, Thelen A, Petersen M (1999) Fungal elicitor preparations and methyl jasmonate enhance rosmarinic acid accumulation in suspension cultures of Coleus blumei. Plant Cell Rep 18: 485-489

Sumaryono W, Proksch P, Hartman T, Mimitz M, Wray V (1991) Induction of rosmarinic acid accumulation in cell suspension cultures of Orthosiphon aristatus after treatment with yeast extract. Phytochemistry 30: 3267-3271

Yamamura Y, Ogihara Y, Mizukami H (2001) Cinnamic acid 4hydroxylase from Lithospermum erythrorhison: cDNA cloning and gene expression. Plant Cell Rep 20: 655-662 